\title{
Proposta de primeres classes de català A1 per a francòfons
}

\author{
Estel Llansana Martínez \\ Université de Toulouse II Jean Jaurès \\ estel.llansana-martinez@univ-tlse2.fr
}

Rebut: 14 de maig del 2020

Acceptat: 1 de juliol del 2020

\begin{abstract}
Resum
Aquest article és una proposta d'activitats per a les dues primeres classes de l'any amb estudiants de nivell $\mathrm{A} 1$ de català com a llengua estrangera. L'objectiu és introduir la llengua i la cultura $i$ aprendre a presentar-se, fent que els alumnes siguin actius i s'ajudin entre ells en el procés d'aprenentatge.
\end{abstract}

\section{Objectius}

A França, el sistema universitari permet que tot estudiant pugui canviar d'assignatures, sigui quina sigui la seva disciplina i nivell d'estudis, durant el primer mes de classes. Això fa que el professorat hagi de fer esforços, des del primer dia, per fidelitzar l'alumnat. En aquest sentit, presentem una proposta lúdica d'activitats adreçades a alumnes de nivell A1 de català com a llengua estrangera (CLE) per a les dues primeres classes de l'any, la primera fent servir el programa Kahoot, i la segona centrada en l'enfocament pedagògic del Groupe Français d'Éducation Nouvelle (GFEN).

L'objectiu de les sessions que presentem és doble. D'una banda, es busca motivar els estudiants tot fent que es diverteixin i creguin que el català és amè i fàcil per tal que no canviïn el català per una altra llengua durant el primer mes. De l'altra, evidentment, s'aprofita l'oportunitat per introduir els primers continguts de llengua i cultura perquè tinguin les informacions generals bàsiques sobre el català i els Països Catalans, alhora que aprenen els elements necessaris per presentar-se.

Ambdues sessions tenen una durada de dues hores cadascuna. Atès que la primera sessió és de caràcter introductori en la matèria, ens centrarem sobretot en la segona, l'èxit de la qual es basa en el fet que els estudiants tenen com a llengua materna o habitual el francès, i que sovint també parlen castellà, cosa que fa que ens puguem permetre anar molt més ràpid en aquesta etapa de descoberta de les primeres paraules i expressions. 


\section{Descripció de l'activitat}

El primer dia, després de presentar el funcionament de l'assignatura, durant uns deu o vint minuts, demanem als estudiants que es descarreguin l'aplicació Kahoot al mòbil. Mentre ho fan introduïm l'activitat i els preguntem què saben del català i dels Països Catalans. Quan estan tots a punt, comencem el test amb el Kahoot. Normalment hi participen individualment però també es pot fer per parelles o en grups, i acostuma a durar una hora.

Les preguntes i respostes que projectem estan escrites en català. Les llegim en veu alta i les traduïm si cal, tot i que estan fetes de manera que siguin fàcilment comprensibles. A més, incorporen il-lustracions que també ajuden a entendre de què tracta la pregunta, com es pot veure a la Figura 1. La majoria de les preguntes estan fetes amb una mica d'humor i amb imatges divertides, i tracten aspectes de caire general sobre la llengua i la cultura catalanes: nombre de parlants; estats i territoris on es parla català; festes i tradicions; gastronomia; persones famoses; símbols de cada territori com ara la bandera, l'himne, la Diada, etc.

En línies generals, l'alumnat sempre s'ho passa bé i més tenint en compte que es tracta d'una competició, amb temps limitat, per veure qui respon millor a les preguntes formulades. Ara bé, com que el pas d'una qüestió a l'altra depèn del professor, nosaltres ho aprofitem per poder corregir tranquil.lament cada pregunta i poder fer les explicacions necessàries relacionades amb els aspectes culturals.

Per acabar, durant la mitja hora que queda, donem a l'alumnat un full amb un mapa dels Països Catalans i treballem les lletres i els sons a partir dels noms de lloc més importants: $n y$, $l l, c ̧ . .$. (Catalunya, Espanya, França, Illes Balears, País Valencià). Aprofitem per parlar de les províncies i dels noms de les illes.

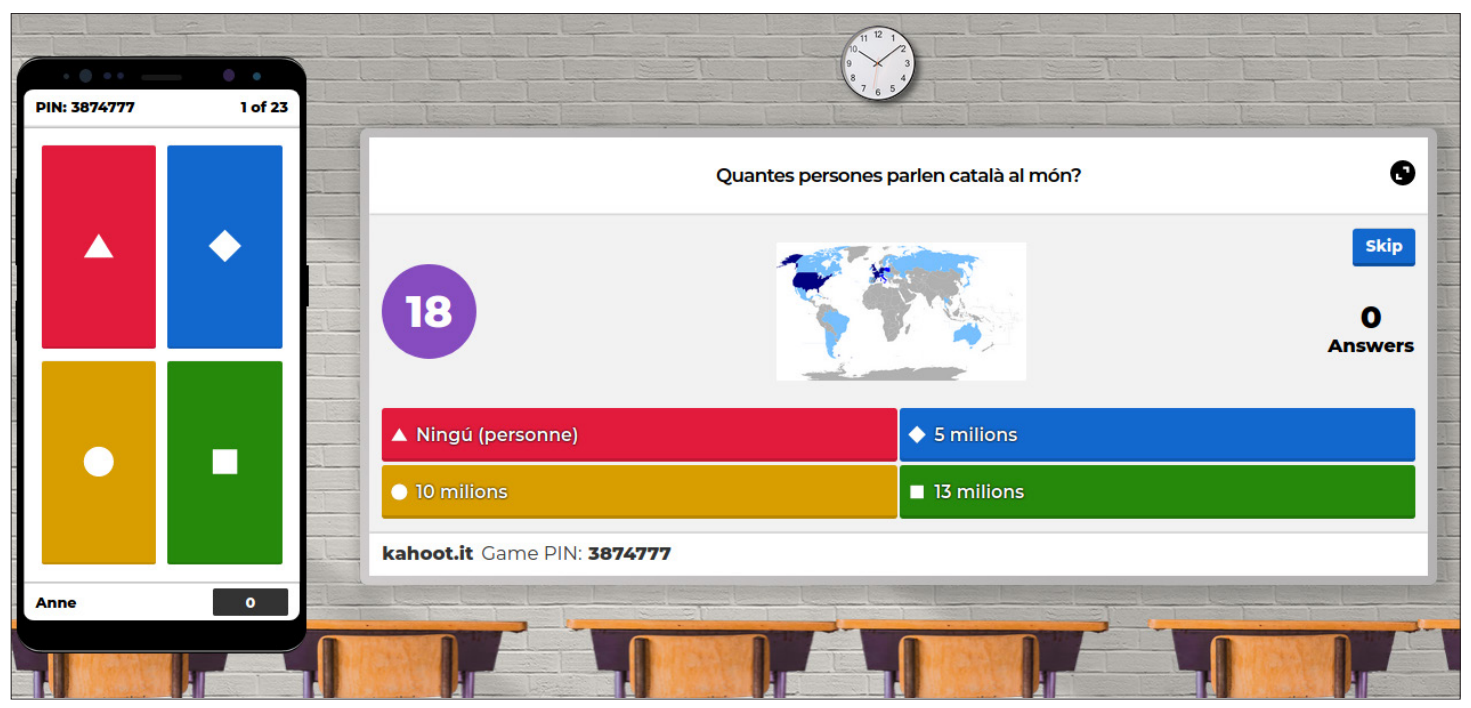

Fig 1. Exemple de pregunta del test amb Kahoot.

El segon dia, treballem com presentar-se. La classe està inspirada en la pedagogia que promou el GFEN. Es tracta d'acompanyar l'alumnat en el seu procés d'aprenentatge de manera que en sigui l'actor principal, actiu i responsable; que vagi construint el coneixement de la llengua a partir del treball individual però també a través de la cooperació amb els altres, per tal de poder fer front a les situacions comunicatives amb el màxim d'eines possible. L'objectiu és treballar, per començar, la comprensió oral i, a poc a poc, la comprensió escrita.

L'activitat es compon de quatre parts d'aproximadament trenta minuts cadascuna. L'objectiu de la primera és saludar i dir el nom; a la segona, els estudiants han de presentar-se individualment amb més detalls; a la tercera cal que presentin el grup, i la darrera és una reflexió sobre els continguts apresos. 
Per començar, durant deu minuts ens passegem per la classe i diem, almenys a deu persones, la frase següent: «Hola, em dic Joan, i tu, com et dius?» Intuïtivament, responen «em dic...» i el seu nom, a la qual cosa responem «Encantat». A continuació, fan grups de quatre o cinc persones, i durant cinc minuts practiquen dins de cada grup preguntant-se el nom i presentant-se els uns als altres. Només ara, si ens ho demanen o creiem que cal, apuntem les frases a la pissarra. Per acabar aquesta primera etapa, durant deu minuts cadascú es presenta a la resta de la classe: «Hola, bon dia, em dic...».

Un cop fet això, a la segona etapa donem una sèrie de materials a cada grup perquè es puguin presentar una mica més i tenen deu minuts per preparar la seva presentació. Com que ha de ser individual, han de compartir els documents i, per tant, poden comentar-los i ajudar-se els uns als altres. Els fulls que donem poden ser els resums gramaticals dels manuals que utilitzem o dels dossiers de classe. En el nostre cas corresponen a les primeres pàgines del seu dossier de classe, però cada professor pot triar els documents que més li agradin. Nosaltres utilitzem una barreja de documents de diferents materials pedagògics: Veus 1, A Punt 1, gramàtica de Parla.cat i materials de creació pròpia, que podeu veure a la Figura 2. Els continguts que hi troben són l'alfabet i els sons; les salutacions; com dir el nom; l'article personal; els pronoms personals; els articles definits; els demostratius; la conjugació dels verbs ser, dir-se, tenir, parlar i estudiar; els números, i

les llengües i nacionalitats.

Passats deu minuts, cada persona es presenta de manera més detallada a tota la classe. Perquè l'activitat no duri més de mitja hora, si són molts, només ho fan uns deu o quinze. A mesura que es van presentant comentem les estructures importants i si hi ha dubtes expliquem com funcionen. Comprovem que el grup classe entén les paraules noves que van apareixent, amb preguntes i comentaris.

La tercera etapa de l'exercici és un treball de grup. Aquesta vegada, els estudiants han de presentar el grup, però no els donem cap consigna sobre com fer-ho. És a dir, són lliures de presentar les persones una per una o de manera conjunta, poden utilitzar ell i ella, ells i elles, nosaltres o vosaltres. Tenen deu o quinze minuts per preparar la presentació. En acabat, durant uns quinze o vint minuts cada grup surt davant la classe i es presen-

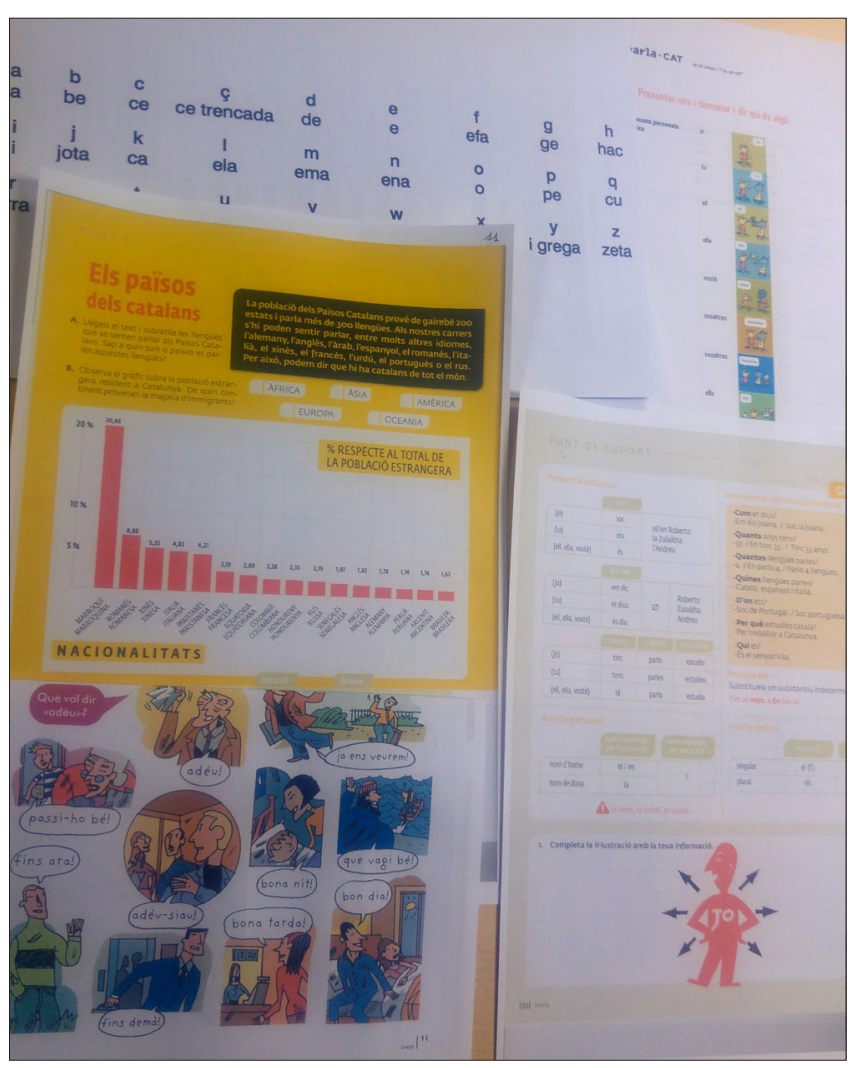

Fig 2. Exemples de documents per les etapes 2 i 3.

ta. Com per a les presentacions individuals, comentem les estructures i el vocabulari que van apareixent, mostrant-los què són capaços de fer només amb un dia de classe.

Per acabar, la darrera mitja hora de classe és l'etapa de reflexió. Preguntem als alumnes què hem après i anem apuntant a la pissarra tot el que ens diuen. Els demanem que conjuguin els verbs, que expliquin el funcionament d'alguns elements (per exemple l'article personal) i resolem els dubtes que hagin pogut sorgir. Els deures solen ser exercicis per repassar els continguts treballats. 


\section{Conclusions}

Per concloure, podem afirmar que aquestes dues classes solen motivar els alumnes, d'una banda perquè les activitats són amenes i participatives, i de l'altra perquè s'adonen que ràpidament són capaços de presentar-se i aprenen continguts de tipus cultural. Tot això fa que sentin que serà divertit i fàcil aprendre català i que decideixin quedar-se. Pel que fa a la primera classe, els despertem la curiositat amb un tast d'informacions bàsiques sobre la llengua i la cultura que sovint no coneixen, s'ho passen bé i surten amb la sensació d'haver après i d'entendre fàcilment paraules en català.

A la segona classe, la clau és que cadascú utilitzi i comenci a assimilar els diferents elements gramaticals i de vocabulari apresos. A partir dels elements orals i escrits que els donem, i havent-los analitzat i ja utilitzat, esperem que l'alumnat dedueixi el funcionament de les primeres nocions de gramàtica, més amb la seva intuïció que no pas amb les explicacions del professor, i que després sigui capaç d'explicar què ha après.

A Tolosa ja fa uns sis anys que fem aquestes classes, amb força grups diferents d'estudiants francòfons, i funciona molt bé. Pensem que és interessant compartir-ne una descripció detallada, per si pot ser útil a altres professors. Les activitats descrites reforcen la confiança dels estudiants en ells mateixos, ja que s'adonen que són capaços d'utilitzar i d'assimilar força coneixements en poc temps, i alhora ajuden a trencar el gel i a crear unes dinàmiques de grup sovint més positives i disteses, que afavoreixen l'aprenentatge posterior.

\section{Bibliografia}

Alejandre Marco, J. (2018). Buenas prácticas en la docencia universitaria con apoyo de TIC: Experiencias en 2017 (pp. 65-72 i 91-102). Zaragoza: Prensas de la Universidad de Zaragoza.

Groupe Français d'Éducation Nouvelle (2001). Repères pour une Education Nouvelle: Enseigner et (se) former. Lyon: Chronique Sociale.

Groupe Français d'Éducation Nouvelle Secteur Langues (2010). Réussir en langues: un savoir à construire. Lyon: Chronique Sociale.

Groupe Français d'Éducation Nouvelle Secteur Langues (2011). 25 pratiques pour enseigner les langues. Lyon: Chronique Sociale.

Parras Cifuentes, M. (2019). La gamificació: una eina educativa per millorar la motivació de l'alumnat (Treball de Fi de Màster). Universitat Pompeu Fabra i Universitat Oberta de Catalunya, Catalunya. Recuperat de http://openaccess.uoc.edu/webapps/o2/bitstream/10609/101009/6/mparrascTFM0519mem\%C3\%B2ria.pdf 